\title{
Exploration of the Historical and Cultural Aspects of "Yuanchangbu" in Chinese Classical Dance
}

ISSN: 2311-8636 (Print)

ISSN: 2312-2021 (Online)

DOI prefix: 10.18034/ajhal

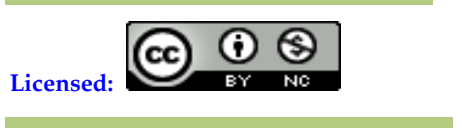

Source of Support: Nil

No Conflict of Interest: Declared

${ }^{*}$ Email for correspondence: xx507@nyu.edu

\section{Xiang Xu}

Dance Department, Tisch School of the Arts, New York University, New York City 11106, USA

\section{ABSTRACT}

The main purpose of this paper is to explore and analyze the unknown Chinese emotions hidden behind the movement "Yuanchangbu," and to find out the meaning behind it from a cultural and historical viewpoint. We will rediscover some of the silences in history and restore the psychology, emotion and movement of Chinese classical dance. Therefore, this paper will, firstly, set "Yuanchangbu" as a clue through which to explore how the movement in daily life developed into the movement of Chinese classical dance. Furthermore, due to the impact of ancient Chinese foot binding culture on the formation of "Yuanchangbu", this paper, based on research of the movement, will also explore the era of foot binding. We will understand the changing progress of Chinese men and women's lifestyle from the era of the natural-foot to foot binding. And at this moment trigger further thought on the culture and style of Chinese traditional dance by the "foot-binding culture."

Key Words: Classical dance, foot binding, Yuanchangbu

\section{INTRODUCTION}

To thoroughly understand the intrinsic and core value of classical art, we should start with the whole historical and cultural context, and explore its internal value that was present in its evolution from the beginning of its appearance to modern society. And in different stages of its evolution, there will be some special historical factors that will make its pattern vary. For Chinese classical dance, we should not only clearly understand the background formed in history but also most importantly narrow the whole background of the dance's developmental history down to every single movement and psychological feature of classical dance, which will be the base of our study on classical dance's historical origins and development threads. And therefore, we will be able to find out how many threads are affecting the evolution from daily life movement to dancing art exist behind those psychological pathways and patterns. Not only can we research classical dance from a historical and culturally appropriate viewpoint of dance, but also from the human being's body movement. Knowing this we can understand why our ancestors were such eloquent dancers and why those body movements created ways of expressing emotion. 
In different ages, Chinese culture had different styles, and we should explore the intrinsic culture behind it on the basis of movements and postures. Analyzing from the view of Chinese traditional dance movements, its various dance steps affect the whole body of dancers. Among those dance steps, the most representative one is "Yuanchangbu"1.

${ }^{1}$ [A traditional Chinese dance step which literally means walking around the stage]

This paper will analyze these movements grounded in different dynasties and their histories, by which we can realize its advantages and disadvantages on cultural aspects, and hereby provide some suggestions for the development of Chinese traditional dance in a new era.

"Yuanchangbu" was developed from the movements of Chinese traditional opera. To figure out the emotion and psychology of the Chinese dancers behind "Yuanchangbu," we should first find out the relationship between the period of a natural foot and binding foot in Chinese culture. It is an important aspect to consider when thinking about Chinese traditional dancing culture that was perpetuated and solidified by the physicality of the feet in ancient Chinese women.

\section{EXPLORATION OF FEATURES OF FEMALES WITH BOUND FEET TRIGGERED BY YUANCHANGBU ${ }^{2}$ CULTURE IN DIFFERENT DYNASTIES}

${ }^{2}$ [A traditional Chinese dance step which means walking around the stage]

According to some historical records, although we cannot make certain the exact period when women had to bind their feet, it is confirmed that the Chinese tended to pursue tiny feet in different dynasties. It says that Qin Shihuang (259-221 B.C.), the first emperor of the Qin Dynasty, listed tiny feet as one of the standards of beauty. There is also a story about a marquis of the Qi State in the Southern Dynasty (420-589A.D.), whose posthumous name is "Donghunhou" (483-501A.D.). One of his concubines named Pan had a pair of feet, which were as tiny as petals of a lotus flower. When she walked around, lotus flowers seem to blossom on the floor. Another example is Yao Niang, a famous concubine who lived in the Five Dynasties Period (907-960A.D.), who often bound her feet and danced on a stage, which was lotus-like in shape. From those historical events, we can gather information that Chinese men have always had a tender affection for women with tiny feet. As for the art of dancing, women are always its main force, and having a pair of naturally tiny feet is the premise for dancing. However, there is a different age-the age of bound feet. Women in that period suffered from foot binding for the purpose of winning the love of men. Due to the impact of foot binding, dancing culture in that period reflected its stigma of the time. We noticed that in Chinese operas, folk dances of Han Chinese, and traditional dances, reflected an interesting movement called "Yuanchangbu." Nearly every step of it requires the dancers to close the inner sides of their knees. Therefore, the dancers' steps should be small, fast and even, and the upper part of the body should be steady. This specific body movement has strong features of Chinese culture. The historical and cultural concepts behind it are abundant and complex. From the aspect of time, Chinese traditional opera was formed about three hundred years ago. But some of the actions and postures of Chinese traditional opera derive from dancing culture which existed in the period before the Ming Dynasty (1368 1644 A.D.), while some of them originate from folk dance and martial arts. And some others were developed from movements in daily life to postures on stage. These are all aspects of the multiple sources of art, which integrated into Chinese traditional opera. It is generally known that after the Five Dynasties Period, Chinese palace dance started to decline. From the Song Dynasty (960-1279A.D.), Chinese traditional opera was gradually shaped into a highly integrated pattern of art. And from the performance and postures of 
Chinese traditional opera, we can intuitively feel the ethos, which occurred during the Song and Ming Dynasties. Therefore, the art shows products of an Abstinence culture, which was impacted by neo-Confucianism. That will make us deduce that the movement, posture and mentality of Chinese traditional opera are merely expressing features of the period when Chinese traditional opera already existed. For example, many people think the "Yuanchangbu" in Chinese traditional opera appeared during the Song Dynasty and, therefore, is the product of the era that women bound their feet. However, researching historical records, I found that there are problems in such a deduction. In this paper, I will analyze the development of this culture and its impact on Chinese dance.

\section{Features of woman with bound feet in the Song dynasty (960-1279A.D.)}

Firstly, many people think Chinese women started to bind feet since the Song Dynasty. However, I want to point out that women hadn't bound their feet in the early Northern Song Dynasty because we have no record showing that the custom of foot binding existed at that time. It is confirmed that the custom of foot binding existed between 1068A.D. and 1085 A.D., even though there were still not too many women who bound their feet. Therefore we can infer that the custom of foot binding started from about the 11th century. The custom of foot binding significantly developed during the period of 1119A.D. to 1125A.D. From figure painting materials we can see that females in the Northern Song Dynasty (960-1127A.D.) seldom bound their feet. For example, most women in the Northern Song Dynasty, which are described in the Dunhuang Murals have natural feet. During the period of the Southern Song Dynasty (1127-1279A.D.), the custom of foot binding had significantly developed, and women's shoes at that time were comparatively smaller than before. Archaeological researchers also found some shoes of women with bound feet. Accordingly, we can infer that there were many women with bound feet in the Southern Song Dynasty. In the late Southern Song Dynasty, binding feet had become almost a surname of women, being addressed by the term "bound foot" in their title before their name. However, it was still not common for women to bind their feet in the Southern Song Dynasty. During the Yuan Dynasty (12711368A.D.), there were still some aristocratic women with natural feet. In conclusion, in the late Southern Song Dynasty, not all people thought that women should bind their feet.

$\mathrm{Su}$ Dongpo, a famous Chinese poet who lived during the middle term of the Northern Song Dynasty, wrote the lyric for a tune, which is named "Song of Buddha-like Exotic Dancers". That lyric was the first Chinese poetry describing bound feet. The appearance of such poetry is proof of the beginning of foot binding custom, and many materials show that the custom of foot binding existed during the middle term of the Northern Song Dynasty. However, strictly speaking, the bound feet in the Song Dynasty are different from the "lotus feet" which appeared afterwards. From The History of Song, we can find records on bound feet of palace women. From that record it can be seen that bound feet should be slim and straight. They were called "Kuaishangma"3 at that time.

${ }^{3}$ [Kuaishangma, which can be literally interpreted as "as swift as riding on a horse", is a type of bound feet, which enable women to walk lightly and lissomely]

As for women's shoes, there was a kind of shoe called "Cuodaodi". "Cuodaodi" had a pointed sole and consisted of two colors. During the excavation of some graves built in the Southern Song Dynasty, archaeologists found some shoes for bound feet, the length of which is about $13-14 \mathrm{~cm}$, or even bigger ${ }^{4}$.

${ }^{4}$ [Gao Hongxing, The history of foot binding, (Shanghai Literature and Art Press, 2007), P. 21, Para. 2] 
Obviously, such shoes in the Song Dynasty are bigger than shoes for "lotus foot" which are less than $10 \mathrm{~cm}$ in length. Besides, although foot binding had appeared in the middle and late term of the Song Dynasty, women at that time had relative freedom to choose whether or not to bind their feet. There were not too many standards and requirements on bound feet at that time. The function of foot binding was just to make feet slimmer and straighter, and there were not strict requirements on the size of bound feet, which could be bigger than "lotus foot". From that phenomenon we can see that women in the Song Dynasty were just in the stage of forming their appreciation for bound feet. Therefore, when facing the problem of foot binding, women in the Song Dynasty did not suffer psychologically and physically like women in the period of "lotus foot", whose feet were tortured and nearly disabled. What's more, only aristocratic women bound their feet. Prostitutes did not have to in the Northern Song Dynasty, although some prostitutes imitated aristocratic women in binding their feet. Nevertheless, females in traditional families did not bind their feet, and even some aristocratic women did not either. Since then, the custom of foot binding lasted from the Song Dynasty to the end of the Qing Dynasty (1636-1911A.D.), which spread too many areas, from North to South, from a small area to the whole country. And the size of bound feet changed from comparatively big too small. The shapes ultimately became slimmer, and changed from straight to bend.

\section{Features of woman with bound feet in the Yuan dynasty (1271-1368 A.D.)}

The rulers who built up the Yuan Dynasty were Mongols, who did not bind feet at first, but eventually did the opposite and even supported Han Chinese women to bind their feet. Perhaps the rulers of the Yuan Dynasty agreed on such matters of Chinese aesthetics to win the support of the Chinese and thus keep ruling Mainland China. This attitude could enhance their dominion and persuade some Han interest groups to support them. Therefore, it was a political purpose that motivated the Yuan Dynasty's rulers to agree on foot binding culture. And that purpose made Mongols permit and even support Han Chinese women to bind their feet. One example of that phenomenon is that there was poetry written under the order of the emperor aiming at praising bound feet. In the Yuan Dynasty, women's bound feet continued to develop in the direction of smaller and slimmer. However, despite the development of foot binding culture, there were still many women, especially in south China, without bound feet. And similar to the Song Dynasty, even some aristocratic women did not bind their feet. As for Mongolian women, they were somewhat affected by that custom, yet that kind of effect was not significant.

\section{Features of woman with bound feet in the Ming dynasty (1368-1644 A.D.)}

During the Ming Dynasty, there was a period when people worshiped the culture of binding feet and set "lotus foot" as a standard which required women's feet to be small, bent and even in the shape of rice dumplings. This is a further development on foot binding culture in the time before the Song Dynasty. In the Ming Dynasty, bound feet had become the standard of classifying women's social status. Depending on the interest and support of the emperor, aristocratic women including women in the palace and queens all tended to bind their feet. Foot binding was a way to potentially restrict the movement of the female body. More scholars started to praise the grace of women with bound feet, and brought out various so-called aesthetic standards, which were based on chauvinism. People even treated playing with women's bound feet as an enjoyment as well as a method to improve their interests in sex. Traditionally, it is the first step of sexuality when a man touches the feet of a woman. Since men judged women with chauvinism, many of them were addicted to bind feet. They established many standards to appreciate bound 
feet; methods to play with them and even absurdly poured alcohol on bound feet for drinking. From the Ming Dynasty, Chinese women used foot binding to improve and maintain social status. Bound feet closely influenced all aspects of their life, and became an unseen law that restricted the body of women. That phenomenon did not exist until the start of the Ming Dynasty. In the late Ming Dynasty, as the formation of opera, the aesthetics of bound feet were reflected in the art of opera. In Shanxi Province and northeast China, the custom of foot binding prevailed. Due to its influence, performers of opera imitated the movement of women with bound feet. After being lifted upon stilts, the performers became elegant and feminine, which the audience welcomed.

\section{Features of females with bound feet in the Qing dynasty (1636-1911A.D.)}

The Qing Dynasty is a period of great prosperity for bound feet even while most Manchu women did not bind their feet. The rulers of the Qing Dynasty opposed the custom of foot binding and repeatedly forbade it. Therefore, Han Chinese women were the adherents of bound feet. By the requirement in the Ming Dynasty that feet should be no more than $10 \mathrm{~cm}$ in length, scholars in the Qing Dynasty brought out more strict standards for bound feet, and more techniques appeared on foot binding. There were seven basic standards for bound feet: small, skinny, pointed, bent, fragrant, and soft and being in good shape. At that time, almost all women in areas inhabited by Han Chinese bound their feet, even common among the minority groups residing in northwest and southwest China. Furthermore, scholars in the Qing Dynasty wrote poetry in praise of the elegance of women with bound feet. Meanwhile, it was common that many male dancers played female roles in folk dances in areas inhabited by Han Chinese. Male dancers wore "Cunzi" to imitate the movement and emotion of woman. The most typical folk dances of that kind are "Huagudeng" in Anhui Province and "Yangge"7 in Haiyang City. During the development of operas in the late Qing Dynasty, a performer of "Qinqiang" ${ }^{8}$, named Wei Changsheng, introduced the stilt, which is a prop in operas popular in northwest China and Shanxi Province, to the Beijing Opera.

${ }^{5}[$ Cunzi is a piece of wood in the shape of a tiny foot, and about $30 \mathrm{~cm}$ in height. Male dancers can walk on them, cover them with their trousers and pretend that their feet were as small as women's]

${ }^{6}$ [Huagudeng is a type of folk dance, which is a combination of dance, singing, and drum striking]

'[Yangge is a type of folk dance, which demonstrates how farmers work in the field]

${ }^{8}$ [Qinqiang is a type of opera popular in northwest China]

Together with the movements in Beijing opera, the stilts help male dancers to imitate the postures of females successfully. That technology became popular and representative. In that period, women with bound feet represented beauty in the value of men. That viewpoint reflected in the expression of arts and affected the value of the audiences in a less noticeable way.

There are five reasons women decided to bind their feet. Firstly, the traditional theory of Yin and Yang ${ }^{9}$ defines female as soft and diminutive, which is different from the definition of male.

${ }^{9}[$ Ancient Chinese used the word Yin to stand for things that are negative, feminine, dark, weak, soft, and so on. And they used the word Yang to stand for things, which are positive, masculine, bright, strong, tough, and so on.]

Secondly, the feudal ethical code suppressed women by torturing their body, and Neo Confucianism restricted the action and freedom of women. Those factors made woman obedient, deprived their freedom of walking out of their houses, maintained their loyalty to their husbands, and hereby finally made women to be possessions of men. 
Thirdly, as man identified with the culture of foot fetishism and connected sexuality with small feet, watching woman with bound feet walk on the street or playing with bound feet gave them sexual excitement and satisfaction. Fourthly, the whole society judged the appearance of women by the standard of bound feet and used marriage, social status and other invisible forces as tools to force women to accept bound feet.

The fifth factor is the influence of aristocratic classes. Women focused on securing their ascendance with bound feet. The reason was the poor women could already hardly make their living and thus were unable to beautify themselves with bound feet, as bound feet made walking difficult and, therefore, would have been an additional burden on a poor woman's ability to walk. Therefore, the influence of the upper class, the interests of the emperors, and the praise of scholars naturally made foot binding the culture norm in society.

\section{ANALYZING THE FORMATION OF YUANCHANGBU FROM A HISTORICAL VIEWPOINT}

In this paper, I have discussed the historical features of the bound feet era in the order of different dynasties from the Song Dynasty to the Qing Dynasty. By comparing these periods, we found out that the culture of foot binding was in fact formed in the Ming Dynasty, and peaked in the Qing Dynasty. The Song and Yuan Dynasties were just the era when bound feet began to appear. Therefore, from the aspect of foot binding culture, women's psychological states and physical features in the Song and Yuan Dynasties are obviously different from those in Ming and Qing Dynasties. It is reckoned that opera was formally established in the middle term and late term of the Ming Dynasty, which indicates that if Yuanchangbu were created to imitate women with bound feet, then it would be formed in the Ming Dynasty. However, these few deductions correspond to the formation period of Yuanchangbu's genuine form. If we go back to the times before the Song Dynasty, it can be found that there were already some direct and indirect factors that affect the formation of Yuanchangbu. In the eyes of the ancient Chinese, women's bound feet were small and could be gripped, which could trigger the tender feelings of men. Women with bound feet walked unsteadily and shyly, which could also initiate men's fantasies. There were two types of beauty in ancient China. The representation of the first type is Zhao Feiyan, who was the favorite concubine of HanChengdi ${ }^{10}$.

${ }^{10}$ [Han Chengdi (51-7B.C.), the 9th emperor of Western Han Dynasty]

She was slim. The second representation was Yang Yuhuan, who was the favorite concubine of Tang Xuanzong ${ }^{11}$.

${ }^{11}$ [Tang Xuanzong (685-762 B.C.), the $6^{\text {th }}$ emperor of Tang Dynasty]

She was chubby. Although they were beauties of different types, both of them had small feet. Even before the Five Dynasties period (907-960 A.D.), women who had natural feet appreciated the small sized feet. For example, Zhao Feiyan and Yang Yuhuan could walk slowly and elegantly due to their small feet, which triggered the fantasy for men. In that period, people only appreciated small sized feet, but did not force women to bind their feet. From historical records we discover that even before the Song Dynasty there existed potential factors, which later influenced the later popularity of "lotus foot" in the Ming Dynasty.

\section{CONCLUSION}

The psychology and expression of every dance movement contains that nation's unique character and unique way of thinking. The emotions and movements of Chinese classical dance are full of the memories of our ancestors. Memory is just like human gene. Every 
seemingly familiar movement actually contains a genetic code of the Chinese people. They hide behind every dance movement and only if we can decode them are we able to understand the aesthetics of Chinese classical dance in education and on stage. Be it for teachers who are teaching in class or choreographers who are creating dance works, such knowledge can make them understand the unique psychology and bodily expressions of the Chinese people. It is also a necessary instrument to create the standards for a unique dance culture system.

In this paper, I introduce Yuanchangbu as a typical representative of dance steps in classical dance and then research and analyze its historical and cultural background. My purpose is to narrow the broad aspects of the development of dance history down to the nucleus of classical dance. On the basis of the forms and psychological features of all kinds of single movements, I thoroughly researched its historical origin and its threads of development. Thus, I discover in these psychological and physical expressions a multitude of aspects of the Chinese body culture aesthetics. I think that such explorative research on traditional dancing art is extremely helpful for understanding its present state and for developing it further. As for the research on traditional dancing culture, my opinion has always been that we must start by researching dancing art itself, and then continue into aspects such as philosophy, morals, religion, customs and other art subjects. In this way, we can understand and analyze it in an interdisciplinary way. Based on results of this research, I researched the culture of folk dance, opera and classical dance in different dynasties and studied the subject of art from the background of history and culture, and then narrow down the research to the subject of classical dance. I believe that the result of this research can help us figure out how to inherit and develop the art of classical dance.

That is the only way we can learn the advantages from various arts and apply them to strengthen the meaning of that traditional subject of art. However, in order to research and analyze dancing culture from the angle of classical dance, I think that we should start from the historical and cultural aspects. The pathway of exploration is arduous and long, which is a fortune and a challenge for the Chinese who come from a country with rich cultural history. Since there is an abundance of research material, we should seriously consider how to make use of those resources to improve our dancing culture. Many young dancers deem practicing as the only method of study or tend to study with the thought of a Westerner. They are reluctant to learn the spirit of traditional culture. Therefore, when studying traditional dancing culture, they lack the corresponding knowledge. Consequently, they use Western aesthetics or what they consider being traditional culture to rebuild the so-called typical traditional dancing culture. That is incorrect. If the original form and aesthetics of a culture is decomposed in a wrong way, we cannot rebuild or recover it correctly. Therefore, if we want to inherit and develop traditional culture, we should research it critically and ponder over it holistically. That is the only way that traditional dancing art can be inherited, grown and appreciated in modern China.

\section{REFERENCES}

\section{Books}

CaiLihong, Research on dance and song in Ming Dynasty, (The Straits Literature and Art Press, 2007)

GaoHongxing, The history of foot binding, (Shanghai Literature and Art Press, 2007)

Huang Yufu, The relation between stilts and Chinese gender, (Life, Reading, New Knowledge Sanlian Book Store, 1998)

Liu Chengji, Research on esthetics on body in Han Dynasty, (People's Press, 2007)

Liu Linda, Sex and Chinese culture, (People's Press, 1999)

Qin Yongzhou, The history of Chinese social custom, (Shandong People's Press, 2008)

Sun Ying, General research on Chinese dance in Han Dynasty, (Chinese Literature Joint Press, 2010) 
Wang Kefen, The history of Chinese dance's development, (Shanghai People's Press, 2004)

Ye Lang, A general outline of the history of Chinese esthetics, (Shanghai People's Press, 1985)

Yu Huimin, Noble women, (National Pictorial Press, 2004)

Yuan He, Text book on the history of Chinese ancient dance, (Shanghai Music Press, 2004)

\section{Journals}

Deng Rubing, 'Changes in Women's Dress in the Late Qing: Women's Body and the State and the Fashion-Starting from Unbinding the Feet', (2006) 5 Collection of Women's Studies

GaoQian, Li Yajuan, 'Discussion on the living status of Chinese women in Neo Confucianism culture - take the foot culture as an example' (2009) 11 Anhui Literature

Liu Jianbo, 'A study to the woman features in the literature of Dynasties pre-Qin, Qin and Han under the visual angle of feminism', (PhD thesis, Shandong University 2008)

Liu Qingyi, 'The basic scope and concept of Chinese classic dance', (2006) 2 Journal of Beijing Dance Academy

Ma Fuqiang, 'Discussion on the new Chinese classic dance's spirit in dances in the Han and Tang Dynasties', (2008) 2 Forum of Arts

Ma Xiao, 'Research on the differences and similarities between Chinese classic dance and Chinese opera', (2009) 8 Journal of Chifeng University (Philosophy and Social Science)

$\mathrm{Mo} \mathrm{Li,} \mathrm{'Research} \mathrm{on} \mathrm{female} \mathrm{political} \mathrm{consciousness} \mathrm{of} \mathrm{the} \mathrm{Taiping} \mathrm{Heavenly} \mathrm{Kingdom',} \mathrm{(2011)} 2$ Innovation

QueHanxiang, 'Discussion on foot-binding', (1996) 4 Social Work

Ren Yan, 'Creating classic dance works should pay attention to its cultural connotation-taking the leaning tower dance in the Han Dynasty as an example', (2011) 8 The Big Stage

Sun Ying, Zhou Zhiqiang, 'Sun Ying's dance: the silent aesthetics revolution-dialogue between Sun Ying and Zhou Zhiqiang', (2005) 4 Journal of Beijing Dance Academy

Wang Haitao, 'Analysis on Sun Ying's artistic value ', (2010) S1 Journal of Southeast University (Philosophy and Social Science)

Wang Rui, 'Discussion of the training value of the step form in classic dance in the Han and Tang Dynasties', (2011) 5 Journal of Guangdong Polytechnic Normal University

Wang Shaohua, 'The Source and Evolution of the Phrase GuoZu' (2002) 2 Journal of East China Normal University (Philosophy and Social Sciences)

Wang Yingze, 'Women who did not bound feet in Ming and Qing Dynasties', (2003) 1 Westleacher

Wei Tianhui, 'Exploration on the reason why women in the Ming Dynasty had low social status', (2009) 4 Lanzhou Academic Journal

Xiang Yunju, 'The painful history on body and its cultural critics --- new theory on Feng Jincai's Lotus Feet' (2010) 17 Argument on Art and Literature

Xiao Yu, 'Sun Ying's viewpoint of national dance', (2000) 4 Journal of Beijing Dance Academy

Yang Juyuan, 'Research on foot-binding', (2003) 2 Chunqiu Birmonthly

Yu Jizeng, 'The rise and decline of foot-binding of woman', (2006) 3 Root Exploration

Zhang Beibei, 'The study of Han Chinese clothing in the Song Dynasty', (PhD thesis, Suzhou University 2010)

Zhou Leshi, 'Female Imagination in the Novels of Late Qing Dynasty (1902-1911)',(PhD thesis, Shanghai University 2010)

Zhu Lingyan, 'Anscramble Foot-binding as Aesthetics Culture', (Master thesis, Zhejiang University 2007)

Zhu Shengqin, 'Modern Chinese discuss about women anti bound feet movement', (2010) 12 Legend Biography Literary Journal Selection

ZouXiaoyan, 'Differences between Chinese and Western dance-discussion by comparing Tai Chi map and The Cross', (2006) 4 Journal of Inner Mongolia Agricultural University (Social Science Edition) 